\title{
Distribution of macro- and micronutrient intakes in relation to the meal pattern of third- and fourth-grade schoolchildren in the city of Quetzaltenango, Guatemala
}

\author{
Marieke Vossenaar ${ }^{1, *}$ †, Gabriela Montenegro-Bethancourt ${ }^{1,2}$, Lothar DJ Kuijper ${ }^{2}$, \\ Colleen M Doak ${ }^{2}$ and Noel W Solomons ${ }^{1}$ \\ ${ }^{1}$ Center for Studies of Sensory Impairment, Aging and Metabolism (CeSSIAM), Guatemala City, Guatemala: \\ ${ }^{2}$ Health Sciences Institute, Vrije Universiteit, Amsterdam, The Netherlands
}

Submitted 21 June 2007: Accepted 15 September 2008: First published online 9 December 2008

\begin{abstract}
Objective: Our objective was to assess the distribution of energy, macro- and micronutrient intakes by meal (breakfast, lunch, dinner and combined snacks) in a cross-sectional sample of schoolchildren.

Design: Cross-sectional dietary survey in schoolchildren.

Setting: Twelve private and public schools in the urban setting of Quetzaltenango, Guatemala.

Subjects: A total of 449 schoolchildren (from higher and lower socio-economic strata) were enrolled in the study.

Methods: Each child completed a single, pictorial $24 \mathrm{~h}$ prospective diary and a face-to-face interview to check completeness and estimate portion sizes. Estimated daily intakes were examined by mealtime as: (i) absolute intakes; (ii) relative nutrient distribution; and (iii) critical micronutrient density (i.e. nutrient density in relation to the WHO Recommended Nutrient Intakes/median age-specific Guatemalan energy requirements).

Results: The daily distribution of energy intake was $24 \%$ at breakfast, $30 \%$ at lunch, $23 \%$ at dinner and $23 \%$ among snacks. Lunch was also the leading meal for macronutrients, providing $35 \%$ of proteins, $27 \%$ of fat and $30 \%$ of carbohydrate. The distribution of selected micronutrients did not follow the pattern of energy, insofar as lunch provided relatively more vitamin $\mathrm{C}$ and $\mathrm{Zn}$, whereas breakfast led in terms of vitamins $\mathrm{A}$ and $\mathrm{D}$, thiamin, riboflavin, folate, $\mathrm{Ca}$ and $\mathrm{Fe}$.

Conclusions: Meal-specific distribution of energy, macro- and micronutrients provides a unique and little used perspective for evaluation of children's habitual intake, and may provide guidance to strategies to improve dietary balance in an era of coexisting energy overnutrition and micronutrient inadequacy.
\end{abstract}

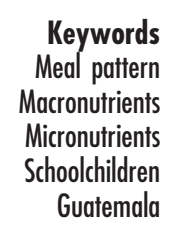

Dietary intake is a major determinant of both the nutritional status and the general health and well-being of an individual. An optimal diet will supply adequate - but not excessive - amounts of all essential nutrients, while maximizing foods and dietary substances that promote long-term health and avoiding dietary constituents related to ill health ${ }^{(1)}$. Both greater dietary variety (number of different foods and beverages consumed) and dietary diversity (selection from an array of food groups) are associated with more nutritious and more healthful intake patterns ${ }^{(2)}$. What is an inherent reality is that foods are consumed in various meals and meal settings over the course of a day. Moreover, factors of household

$\dagger$ Postal address: CeSSIAM in Guatemala, c/o PO Box 02-5339, Section 3163/Guatemala, Miami, FL 33102-5339, USA. *Corresponding author: Email mvossenaar@hotmail.com economics, cultural and culinary conventions and personal convenience will dictate the frequency, size and composition of the meals consumed throughout the day.

A few investigators have analysed individual meal contributions to the day's intake of macro- or micronutrients. These pioneering studies identified dietary patterns that deviate strongly from recommended population nutrient goals in children ${ }^{(3-5)}$, adolescents ${ }^{(6,7)}$ and adults $^{(8)}$. The studies on children and adolescents are mostly European studies. The findings emphasize the difference in nutritional value of meals and the association between breakfast consumption and better dietary quality. Unfortunately, no similar results are available for children or adolescents in Guatemala, or even in the broader region. However, studies show a prevailing trend of snack-dominated meal patterns, associated with higher 
intakes of foods with lower nutrient density (i.e. high in fats and sugars, but low in micronutrients). Further concerns include irregular meal patterns, such as meal skipping, and high fat content in lunch and snacks, patterns to be explored in the present study.

Consumption patterns that are too poor or too rich in macro- or micronutrients, excessive in harmful foods and noxious ingredients, and insufficient in health-protective elements might need to be corrected through education and health interventions. Therefore, knowing the pattern of meals and the nutrient density of these meals might help provide the necessary leverage for corrective change. In Guatemala, micronutrient-enriched products such as micronutrient-fortified cereals as well as sugar fortified with retinyl palmitate are potential major sources of micronutrients for children. However, little is known about how these products are consumed in terms of timing (meal pattern), frequency and quantity.

During a 3-month period in the summer of 2005, $24 \mathrm{~h}$ registries of all food and beverage intake were obtained by interactive, pictorial self-recording by children in the third and fourth grades of public and private schools of the city of Quetzaltenango in the western highlands of Guatemala. Our objective was to assess and describe the intakes of energy and main macronutrients across the different eating opportunities in the children's day, and to relate them the intake of selected micronutrients from the different meals. Below we describe in detail the procedures used to achieve our aim and our findings of meal patterns' nutrient contributions across social class and gender in this survey of urban Guatemalan schoolchildren. Micronutrient density is particularly important in the diet of children, who require nutrient-dense foods for healthy physical and mental development. Identifying the contribution of foods according to meal type is helpful for identifying the relative contribution of microand macronutrients to the diets of children.

\section{Subjects and methods}

\section{Subject selection}

A total of five public schools, stratified as lower socioeconomic status (LSES), and eleven private schools, stratified as higher socio-economic status (HSES), were invited to participate in the study. Within these schools, only children attending third and fourth grades were recruited.

The nature of the study was explained to the teachers and students in the classroom during usual school hours. The children's legal guardians were informed about the study in writing. They were told that the main objective of the study was to assess usual fruit and vegetable consumption in schoolchildren. Incentives to participate included a free snack (either a bread-based meal or cereal) and the children were allowed to keep the crayons provided for the study.
The study was approved by the Human Subjects Committee of the Center for Studies of Sensory Impairment, Aging and Metabolism (CeSSIAM), Guatemala City and the local education authorities. Only children with a signed consent form from their legal guardians were included in the study.

\section{Questionnaire and sample collection}

A single pictorial $24 \mathrm{~h}$ prospective diary was collected from April to June 2005. The data collection instrument is a 5-page booklet designed to assess dietary intake with a $24 \mathrm{~h}$ time frame. The first page contains written instructions on how to complete the questionnaire. The subject is instructed to draw all the food and drink items consumed within a $24 \mathrm{~h}$ time frame and to include all items consumed between meals (snacks) both at school and at home. Children were asked to record all drink and food items consumed since the last meal and for $24 \mathrm{~h}$ thereafter. The children were asked to take the booklets home and draw all food and drinks consumed (including candies) and to specify brands and amounts consumed. On the following day, the subjects were interviewed by a research nutritionist, who checked for completeness and estimated the portions of items listed. This interview helped to clarify the described articles and to quantify the food intake by using food models and common household measures. Children who forgot to bring the workbook were given another booklet for that day and the interview was done the next day. All data were recorded on school days and all meals consumed at school were brought from home or bought at the school snack shop. No school lunch was provided, as a usual school day ends at 13.00 hours.

Although the data collection tool was not validated, the instrument and methodology used for data collection were previously used in studies conducted by CeSSIAM in urban schoolchildren from Guatemala City. The estimated median energy intake for the population, of $7829 \mathrm{~kJ} / \mathrm{d}$ $(1870 \mathrm{kcal} / \mathrm{d}$; data not shown), was in close agreement with the WHO recommendations for this age group ${ }^{(9)}$. Our estimate median protein intake of $65 \mathrm{~g} / \mathrm{d}$ was twice the Recommended Dietary Allowance for this age group ${ }^{(10)}$.

\section{Data analysis}

Each food or beverage item reported was coded and entered into a database according to mealtime (breakfast, lunch, dinner or snack). All food and beverages items were codified separately according to preparation or presentation. Different commercial brand names of fruit juices, readyto-eat cereals, etc. were coded as separate food items. A total of 218 items were listed and their nutrient values were derived primarily from the Central American food composition table (FCT) ${ }^{(11)}$ and secondly from the US Department of Agriculture (USDA) FCT obtained online from the USDA National Nutrient Database for Standard Reference version $16 \cdot 1$ (www.nal.usda.gov/fnic/foodcomp/data). Nutritional 
content of some products, such as ready-to-eat cereals, were updated. Nutrient values for food items not listed in the FCT were taken from the food labels or other manufacturer data. Typical dishes and composite foods were obtained from everyday Guatemalan recipe books ${ }^{(12-14)}$ and their nutrient data were added to the FCT.

In order to provide a context to the food culture of the samples of schoolchildren, an illustration of the selection of the principal food and beverage contributors was assembled. For each meal and as disaggregated by gender and socio-economic status (SES) sub-samples, we calculated the cumulative contribution of energy for each food and beverage item reported within that subgroup. We constructed a $4 \times 4$ panel table by meal and by subgroup, with each panel including the top ten leading contributors to that meal.

The daily distribution of energy, macronutrients and selected micronutrients intakes (vitamin A, vitamin C, vitamin $\mathrm{D}$, thiamin, riboflavin, folate, $\mathrm{Ca}, \mathrm{Fe}$ and $\mathrm{Zn}$ ) throughout the day (i.e. breakfast, lunch, dinner and combined snacks) was examined. The mean absolute nutrient intakes and their standard deviations are provided for reference in the Appendix. The focus of analysis, in accordance with the aim of the study, was to assess the distribution of energy, macro- and micronutrients intakes across meals. The focus here was testing differences between the meals (breakfast, lunch, dinner and combined snacks) within each SES or gender group. It was not our intention to generate comparisons within meals across LSES and HSES and girls and boys.

In keeping with the goal of our study, the analysis focuses first on the percentage of the daily intake of a nutrient that a given meal contributes. Thus, we calculated the subject's consumption of a given nutrient for that meal, divided by the subject's total daily intake of the nutrient and multiplied by 100. These individual mealbased percentages are presented by SES and gender with comparisons of results for meals classified as breakfast, lunch, dinner and snacks. Next, we compared the percentage contribution for nutrients with the meal's contribution to energy intake. These proportions were used for a comparative approach to identify the meals where a particular nutrient contribution fell below the overall energy contribution. If nutrient and energy intakes are proportional, the percentage nutrient and total energy contributions should match, one-to-one. In order to assess nutrients that contributed proportionately above or below the day's nutrient intake, relative to the energy contribution, we arbitrarily defined cut-offs that were $25 \%$ above or below the energy contribution. Thus, a ratio of less than $0 \cdot 75: 1$ identifies the meal as contributing relatively less of a nutrient relative to that meal's energy contribution. An elevated nutrient contribution of greater than $1 \cdot 25: 1$ identifies a meal that contributes proportionately more of a nutrient relative to the meal's energy contribution. For this pattern analysis, we simply tabulated the number of ratios that fell into our preestablished deviant range.

The second analysis, focusing on meal-based nutrient densities, assesses each nutrient relative to the total energy contributed by that meal. Thus, the nutrient consumed at each meal was divided by the total energy. The resulting measure, the meal's nutrient contribution expressed per $4 \cdot 187 \mathrm{~kJ}$ ( $1 \mathrm{kcal}$ ) consumed, was then multiplied by 1000 . As with meal-based percentage intake, energy densities are presented separately for each nutrient, with results stratified by SES and gender, and statistical comparisons are based on differences between the four meals: breakfast, lunch, dinner and snacks.

The final measure compares nutrient densities against estimated nutrient intakes, using a new measure we call 'critical densities' modelled after the 1986 Working Group of the Cavendas Foundation for nutrient requirements in Latin America ${ }^{(15)}$. Critical densities were defined as the estimated recommended nutrient intakes, expressed per $4187 \mathrm{~kJ}(1000 \mathrm{kcal})$, and representing the amount of the respective nutrients that would achieve the recommended intake when an individual consumed the normative daily energy intake for his or her age and gender group. They were computed for selected micronutrients based on the WHO/FAO Recommended Nutrient Intakes $(\mathrm{RNI})^{(16)}$ and the energy requirements for children proposed by the Institute of Nutrition of Central America and Panama ${ }^{(17)}$. The RNI values were 500 retinol activity equivalents for vitamin $\mathrm{A}, 35 \mathrm{mg}$ for vitamin $\mathrm{C}, 5 \mu \mathrm{g}$ for vitamin $\mathrm{D}, 0.9 \mathrm{mg}$ for thiamin, $0.9 \mathrm{mg}$ for riboflavin, 300 dietary folate equivalents for folate, $700 \mathrm{mg}$ for $\mathrm{Ca}, 9 \mathrm{mg}$ for $\mathrm{Fe}$ and $5.6 \mathrm{mg}$ for $\mathrm{Zn}$. These nutrient recommendations were normalized to a $4187 \mathrm{~kJ}$ (1000 kcal) unit based on the estimated daily energy requirements. Thus, recommended nutrient intakes were divided by energy intake needs estimated to be $7850 \mathrm{~kJ}$ (1875 kcal) for boys and $6908 \mathrm{~kJ}$ ( $1650 \mathrm{kcal})$ for girls. Mean nutrient densities of gender and SES subgroups for each mealtime were then compared with the estimated critical densities, based on group means. Mean estimated intakes below the computed critical densities were considered inadequate.

\section{Statistical methods}

Data were analysed with the SPSS statistical software package version $11 \cdot 0$ (SPSS Inc., Chicago, IL, USA). As described above, the analysis focuses on the daily distribution of energy, macronutrients and selected micronutrients intakes (as a proportion of total daily intake) and nutrient densities, per meal. We used repeatedmeasures ANOVA to examine statistically significant differences in daily nutrient intake distributions and nutrient density distributions between mealtimes (i.e. breakfast, lunch, dinner and combined snacks) within subjects. The focus is testing differences between the meals within each SES and gender subgroup. We considered a probability of $5 \%$ to be significant. 


\section{Results}

\section{Study population}

All five public schools and seven schools invited agreed to participate and were included in the study. The total number of schoolchildren attending third and fourth grades in these twelve schools was 1124 (624 LSES, 500 HSES) and the majority of children were between 8 and 10 years old. A large proportion of children ( $n$ 675, 60\%) did not participate in the study for various reasons such as falling outside the age criteria, absence on the day of data collection, 'forgetting' the consent form or leaving the data collection booklet at home. The final sample comprised 449 (40\%) children, 219 (49\%) of LSES (113 girls and 106 boys) and 230 (51\%) of HSES (119 girls and 111 boys).

\section{Principal energy sources of one day's meal- associated intakes}

In order to understand the nutritional partition among meals, it is important to know the context of the foods in the meals. Table 1 presents the ten principal food and beverage contributors to the total energy of each class of meal: breakfast, lunch, dinner and snacks. A modal breakfast comprised breakfast cereals and milk with added sugar. Corn tortillas or white bread with fried eggs were also commonly eaten, especially by LSES children. Corn tortillas, a staple food consumed in all three meals, contributed up to $17 \cdot 5 \%$ of the total energy in LSES boys for lunch. Main energy sources for lunch included chips, white rice and vegetable stew with chicken or beef. Main energy sources for dinner included corn tortilla, sweet bread, coffee with added sugar and fried eggs. Popular snacks included pizza, white bread, crisps and cola drinks.

\section{Estimated proportion of one day's energy and macronutrient contribution by mealtime}

Means of estimated $1 \mathrm{~d}$ intakes of energy and macronutrients by mealtime (i.e. breakfast, lunch, dinner and snacks) are presented as proportions of total daily intake in Table 2. We used repeated-measures ANOVA to examine differences in energy, macronutrient and selected micronutrient distributions between mealtimes (breakfast, lunch, dinner and combined snacks) within subjects. Meal compositions were compared within each of the four subgroups, i.e. HSES boys, LSES boys, HSES girls and LSES girls. Analyses were run separately, testing meal pattern contributions for energy, protein and fat. Of these twelve computations, a significant difference was found in the meals for all macronutrients $(P<0 \cdot 001)$ except fat in LSES girls $(P=0 \cdot 194)$. Lunch led in terms of energy $(P<0 \cdot 001)$, protein $(P<0 \cdot 001)$ and carbohydrates $(P<0 \cdot 001)$, in all gender and SES subgroups. Lunch led in terms of fat in HSES boys $(P<0 \cdot 001)$, whereas breakfast in LSES boys $(P=0 \cdot 038)$ and dinner and snacks in HSES girls $(P=0 \cdot 022)$ were more important sources of fat. Mean energy intake from lunch ranged from $2319 \mathrm{~kJ}$ ( $554 \mathrm{kcal} ; 32 \%$ of energy) in LSES girls to $2700 \mathrm{~kJ}$ ( $645 \mathrm{kcal} ; 29 \%$ of energy) in HSES boys. Dinner and snacks were the lowest sources of energy. Mean energy intake from snacks was between $1562 \mathrm{~kJ}$ (373 kcal; $19 \%$ of energy) in LSES girls up to $2244 \mathrm{~kJ}$ ( $536 \mathrm{kcal} ; 27 \%$ of energy) in HSES boys (Appendix). With respect to the macronutrient:energy ratios, there were few, if any, ratios outside the established boundary limits for the meal-wise fat:energy and carbohydrate:energy percentage ratios. For protein, however, the ratio approached, but did not exceed $1 \cdot 25$, for lunch across the subgroups, and fell clearly below the 0.75 limits for snacks (data not shown).

\section{Estimated proportion of one day's micronutrient contribution by mealtime}

Means of estimated $1 \mathrm{~d}$ intakes of selected micronutrients by mealtime (i.e. breakfast, lunch, dinner and snacks) are presented as proportions of total daily intake in Table 2. We performed within-column repeated-measures ANOVA among the percentage contributions of the four meals for the thirty-six quartets of data involving micronutrients (nine micronutrients by gender and SES). Of these thirty-six computations, a significant difference within the foursome was found for all micronutrients examined $(P<0 \cdot 001)$. In general, although lunch led numerically in terms of energy and most macronutrients, it was not the most micronutrient-dense meal. Lunch was the leading source only for vitamin $\mathrm{C}$ and $\mathrm{Zn}$ in all gender and SES subgroups and folate for LSES girls only. Breakfast led in terms of all other micronutrients examined (i.e. vitamin A, vitamin $\mathrm{D}$, thiamin, riboflavin, folate, $\mathrm{Ca}$ and $\mathrm{Fe}$ ) for all gender and SES subgroups. In general, snacks were the poorest source of all micronutrients.

Turning to a less formally statistical pattern analysis for micronutrients, the 144 ratio values for the percentage contribution of the three macronutrients and nine micronutrients to their corresponding mealtime percentage energy contribution for each specific meal were examined with respect to the boundary criteria. A total of seventy-nine (55\%) were acceptably close to the nutrient:energy contribution concordance ratio of 1:1. An additional thirty-seven (26\%) fell below $0 \cdot 75: 1$ and twenty-eight (19\%) were above 1·25:1 (data not shown). Protein:energy ratio in snacks was an example of a consistently below-criterion ratio, as were the corresponding ratios for vitamin D:energy at lunch and in snacks. In general, snacks had the lowest energy contribution ratios for micronutrients, and this was consistent across all gender and SES groups for vitamins $\mathrm{A}$ and $\mathrm{D}$, thiamin and $\mathrm{Zn}$. Breakfast was often a meal in which the nutrient: energy contribution ratios greatly exceeded the boundary criterion, a pattern that was consistent across all gender and SES groups for vitamins $\mathrm{A}$ and $\mathrm{D}, \mathrm{Ca}$ and Fe. 


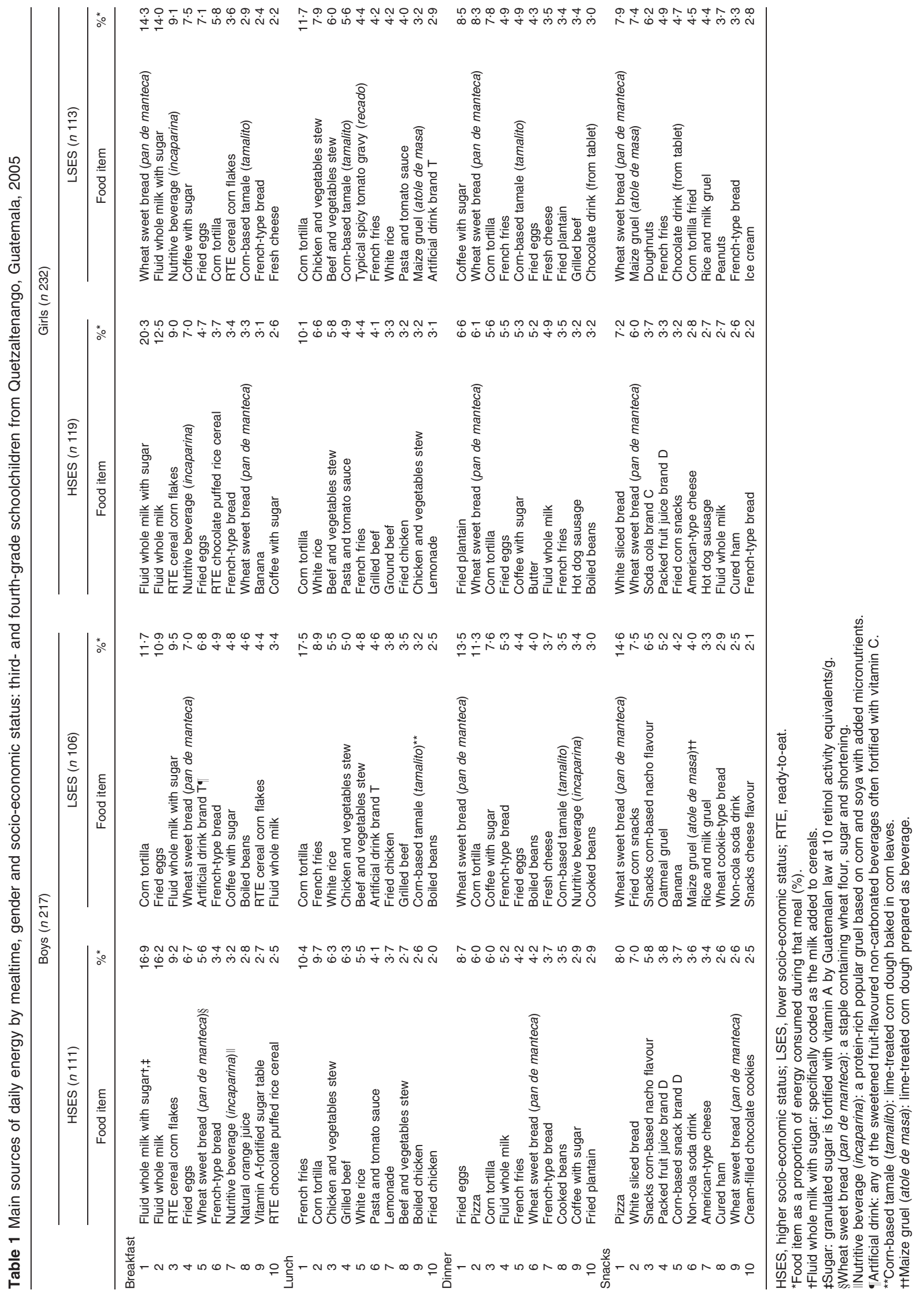


Table 2 Distribution (as a proportion of total daily intake) of estimated $1 \mathrm{~d}$ intakes of energy, macronutrients and selected micronutrients by mealtime, gender and socio-economic status: third- and fourth-grade schoolchildren from Quetzaltenango, Guatemala, 2005

\begin{tabular}{|c|c|c|c|c|c|c|c|c|c|c|c|c|}
\hline & \multicolumn{6}{|c|}{ Boys ( $n$ 217) } & \multicolumn{6}{|c|}{ Girls (n 232) } \\
\hline & \multicolumn{3}{|c|}{ HSES ( $n$ 111) } & \multicolumn{3}{|c|}{ LSES $(n$ 106) } & \multicolumn{3}{|c|}{ HSES ( $n$ 119) } & \multicolumn{3}{|c|}{ LSES ( $n$ 113) } \\
\hline & Mean & SD & $P^{\star}$ & Mean & $\mathrm{SD}$ & $P^{\star}$ & Mean & $\mathrm{SD}$ & $P^{\star}$ & Mean & $\mathrm{SD}$ & $P^{*}$ \\
\hline \multicolumn{13}{|l|}{ Energy } \\
\hline Breakfast & 22 & 9 & & 27 & 12 & & 21 & 10 & & 25 & 10 & \\
\hline Lunch & 32 & 12 & & 30 & 10 & & 29 & 9 & & 29 & 11 & \\
\hline Dinner & 23 & 11 & & 23 & 11 & & 22 & 10 & & 25 & 10 & \\
\hline Snack & 23 & 11 & $<0.001$ & 19 & 11 & $<0.001$ & 27 & 13 & $<0.001$ & 21 & 12 & $<0.001$ \\
\hline \multicolumn{13}{|l|}{ Protein } \\
\hline Breakfast & 21 & 10 & & 30 & 14 & & 22 & 14 & & 25 & 15 & \\
\hline Lunch & 38 & 16 & & 33 & 14 & & 36 & 15 & & 34 & 14 & \\
\hline Dinner & 25 & 15 & & 25 & 14 & & 23 & 13 & & 27 & 14 & \\
\hline Snack & 16 & 14 & $<0.001$ & 12 & 12 & $<0.001$ & 19 & 13 & $<0.001$ & 14 & 11 & $<0.001$ \\
\hline \multicolumn{13}{|l|}{ Fat } \\
\hline Breakfast & 21 & 11 & & 28 & 16 & & 21 & 12 & & 24 & 14 & \\
\hline Lunch & 30 & 16 & & 26 & 16 & & 26 & 14 & & 27 & 17 & \\
\hline Dinner & 25 & 16 & & 24 & 15 & & 27 & 17 & & 26 & 15 & \\
\hline Snack & 24 & 15 & $<0.001$ & 22 & 17 & 0.038 & 27 & 17 & 0.022 & 23 & 18 & $0 \cdot 194$ \\
\hline Carbohydrate & & & & & & & & & & & & \\
\hline Breakfast & 23 & 12 & & 27 & 14 & & 22 & 12 & & 25 & 12 & \\
\hline Lunch & 31 & 14 & & 30 & 12 & & 29 & 12 & & 29 & 12 & \\
\hline Dinner & 21 & 12 & & 23 & 13 & & 20 & 11 & & 23 & 12 & \\
\hline Snack & 24 & 12 & $<0.001$ & 21 & 11 & $<0.001$ & 29 & 14 & $<0.001$ & 23 & 12 & 0.004 \\
\hline Vitamin A & & & & & & & & & & & & \\
\hline Breakfast & 40 & 22 & & 38 & 17 & & 35 & 21 & & 34 & 18 & \\
\hline Lunch & 27 & 23 & & 26 & 20 & & 29 & 21 & & 26 & 19 & \\
\hline Dinner & 25 & 19 & & 22 & 14 & & 22 & 17 & & 24 & 14 & \\
\hline Snack & 9 & 11 & $<0.001$ & 14 & 15 & $<0.001$ & 13 & 14 & $<0.001$ & 15 & 15 & $<0.001$ \\
\hline Vitamin C & & & & & & & & & & & & \\
\hline Breakfast & 29 & 28 & & 26 & 29 & & 24 & 27 & & 17 & 25 & \\
\hline Lunch & 37 & 30 & & 36 & 34 & & 31 & 27 & & 39 & 33 & \\
\hline Dinner & 12 & 17 & & 19 & 25 & & 15 & 22 & & 17 & 23 & \\
\hline Snack & 23 & 29 & $<0.001$ & 17 & 25 & $<0.001$ & 30 & 31 & $<0.001$ & 27 & 33 & $<0.001$ \\
\hline Vitamin D & & & & & & & & & & & & \\
\hline Breakfast & 60 & 27 & & 55 & 36 & & 51 & 33 & & 43 & 39 & \\
\hline Lunch & 10 & 17 & & 12 & 24 & & 9 & 16 & & 12 & 23 & \\
\hline Dinner & 24 & 23 & & 17 & 26 & & 29 & 31 & & 26 & 32 & \\
\hline Snack & 6 & 15 & $<0.001$ & 8 & 21 & $<0.001$ & 10 & 19 & $<0.001$ & 11 & 22 & $<0.001$ \\
\hline Thiamin & & & & & & & & & & & & \\
\hline Breakfast & 31 & 18 & & 33 & 17 & & 32 & 20 & & 29 & 20 & \\
\hline Lunch & 30 & 17 & & 30 & 16 & & 28 & 16 & & 30 & 18 & \\
\hline Dinner & 21 & 15 & & 24 & 16 & & 20 & 17 & & 24 & 16 & \\
\hline Snack & 18 & 15 & $<0.001$ & 13 & 12 & $<0.001$ & 20 & 17 & $<0.001$ & 17 & 15 & $<0.001$ \\
\hline Riboflavin & & & & & & & & & & & & \\
\hline Breakfast & 39 & 21 & & 42 & 27 & & 40 & 23 & & 30 & 25 & \\
\hline Lunch & 26 & 23 & & 24 & 24 & & 20 & 19 & & 29 & 26 & \\
\hline Dinner & 23 & 19 & & 22 & 24 & & 24 & 20 & & 29 & 27 & \\
\hline Snack & 13 & 13 & $<0.001$ & 12 & 16 & $<0.001$ & 16 & 16 & $<0.001$ & 10 & 13 & $<0.001$ \\
\hline Folate & & & & & & & & & & & & \\
\hline Breakfast & 36 & 20 & & 36 & 23 & & 36 & 22 & & 25 & 21 & \\
\hline Lunch & 28 & 20 & & 29 & 22 & & 26 & 20 & & 36 & 24 & \\
\hline Dinner & 20 & 16 & & 20 & 19 & & 20 & 18 & & 22 & 18 & \\
\hline Snack & 15 & 15 & $<0.001$ & 14 & 17 & $<0.001$ & 18 & 17 & $<0.001$ & 17 & 18 & $<0.001$ \\
\hline $\mathrm{Ca}$ & & & & & & & & & & & & \\
\hline Breakfast & 41 & 20 & & 35 & 22 & & 41 & 24 & & 33 & 23 & \\
\hline Lunch & 19 & 15 & & 26 & 18 & & 16 & 14 & & 26 & 18 & \\
\hline Dinner & 24 & 19 & & 24 & 19 & & 23 & 20 & & 24 & 18 & \\
\hline Snack & 15 & 15 & $<0.001$ & 15 & 15 & $<0.001$ & 20 & 19 & $<0.001$ & 16 & 16 & $<0.001$ \\
\hline $\mathrm{Fe}$ & & & & & & & & & & & & \\
\hline Breakfast & 39 & 19 & & 35 & 19 & & 37 & 20 & & 34 & 20 & \\
\hline Lunch & 25 & 15 & & 21 & 14 & & 23 & 13 & & 25 & 16 & \\
\hline Dinner & 22 & 14 & & 25 & 16 & & 22 & 14 & & 21 & 14 & \\
\hline Snack & 14 & 10 & $<0.001$ & 18 & 13 & $<0.001$ & 18 & 14 & $<0.001$ & 20 & 14 & $<0.001$ \\
\hline $\mathrm{Zn}$ & & & & & & & & & & & & \\
\hline Breakfast & 24 & 15 & & 28 & 16 & & 28 & 19 & & 26 & 21 & \\
\hline Lunch & 39 & 19 & & 35 & 17 & & 34 & 19 & & 33 & 19 & \\
\hline Dinner & 23 & 16 & & 23 & 19 & & 22 & 15 & & 25 & 18 & \\
\hline Snack & 15 & 15 & $<0.001$ & 14 & 15 & $<0.001$ & 16 & 16 & $<0.001$ & 16 & 17 & $<0.001$ \\
\hline
\end{tabular}

HSES, higher socio-economic status; LSES, lower socio-economic status.

${ }^{*} P$ value from repeated-measures ANOVA. 
Nutrient density by mealtime

Table 3 illustrates mean values and standard deviations for the selected nutrient densities in each mealtime by gender and SES group. We used repeated-measures ANOVA to examine differences in density distributions between mealtimes (breakfast, lunch, dinner and combined

Table 3 Nutrient densities of estimated $1 \mathrm{~d}$ intakes of macronutrients and selected micronutrients by mealtime, gender and socio-economic status: third- and fourth-grade schoolchildren from Quetzaltenango, Guatemala, 2005

\begin{tabular}{|c|c|c|c|c|c|c|c|c|c|c|c|c|}
\hline \multirow[b]{3}{*}{ Density (per 4187 kJ/1000 kcal) } & \multicolumn{6}{|c|}{ Boys ( $n$ 217) } & \multicolumn{6}{|c|}{ Girls (n 232) } \\
\hline & \multicolumn{3}{|c|}{ HSES $(n 111)$} & \multicolumn{3}{|c|}{ LSES $(n$ 106) } & \multicolumn{3}{|c|}{ HSES $(n 111)$} & \multicolumn{3}{|c|}{ LSES $(n$ 106) } \\
\hline & Mean & SD & Mean & SD & Mean & SD & Mean & SD & Mean & SD & Mean & SD \\
\hline \multicolumn{13}{|l|}{ Protein $(\mathrm{g})$} \\
\hline Breakfast & 34 & 11 & & 36 & 12 & & 32 & 12 & & 31 & 15 & \\
\hline Lunch & 45 & 26 & & 38 & 21 & & 45 & 26 & & 40 & 24 & \\
\hline Dinner & 39 & 20 & & 36 & 22 & & 36 & 19 & & 35 & 21 & \\
\hline Snack & 23 & 16 & $<0.001$ & 19 & 16 & $<0.001$ & 22 & 14 & $<0.001$ & 20 & 14 & $<0.001$ \\
\hline \multicolumn{13}{|l|}{ Fat $(\mathrm{g})$} \\
\hline Breakfast & 30 & 11 & & 30 & 15 & & 28 & 13 & & 28 & 13 & \\
\hline Lunch & 30 & 15 & & 25 & 17 & & 27 & 15 & & 28 & 16 & \\
\hline Dinner & 34 & 17 & & 28 & 16 & & 36 & 18 & & 31 & 15 & \\
\hline Snack & 31 & 15 & $0 \cdot 198$ & 27 & 16 & 0.206 & 28 & 14 & $<0.001$ & 27 & 17 & $0 \cdot 275$ \\
\hline \multicolumn{13}{|l|}{ Carbohydrate (g) } \\
\hline Breakfast & 153 & 34 & & 151 & 40 & & 153 & 47 & & 156 & 38 & \\
\hline Lunch & 143 & 43 & & 158 & 48 & & 150 & 46 & & 154 & 47 & \\
\hline Dinner & 132 & 55 & & 144 & 55 & & 131 & 50 & & 144 & 44 & \\
\hline Snack & 157 & 49 & $<0.001$ & 164 & 58 & 0.034 & 166 & 46 & $<0.001$ & 167 & 55 & 0.003 \\
\hline \multicolumn{13}{|l|}{ Vitamin A (RAE) } \\
\hline Breakfast & 804 & 566 & & 669 & 375 & & 797 & 376 & & 671 & 313 & \\
\hline Lunch & 549 & 969 & & 478 & 664 & & 591 & 548 & & 567 & 779 & \\
\hline Dinner & 517 & 434 & & 420 & 330 & & 543 & 432 & & 496 & 349 & \\
\hline Snack & 234 & 387 & $<0.001$ & 339 & 362 & $<0.001$ & 275 & 309 & $<0.001$ & 383 & 379 & $<0.001$ \\
\hline Vitamin C (mg) & & & & & & & & & & & & \\
\hline Breakfast & 72 & 104 & & 41 & 116 & & 61 & 98 & & 17 & 23 & \\
\hline Lunch & 69 & 115 & & 35 & 50 & & 66 & 103 & & 71 & 138 & \\
\hline Dinner & 28 & 61 & & 19 & 36 & & 30 & 65 & & 22 & 44 & \\
\hline Snack & 85 & 170 & $<0.001$ & 42 & 123 & 0.020 & 89 & 136 & $<0.001$ & 75 & 147 & $<0.001$ \\
\hline Vitamin D $(\mu \mathrm{g})$ & & & & & & & & & & & & \\
\hline Breakfast & $4 \cdot 8$ & $2 \cdot 5$ & & $2 \cdot 6$ & $2 \cdot 3$ & & $4 \cdot 1$ & $2 \cdot 8$ & & $2 \cdot 1$ & $2 \cdot 3$ & \\
\hline Lunch & 0.5 & 0.9 & & 0.4 & 0.8 & & 0.5 & 0.8 & & 0.5 & 0.9 & \\
\hline Dinner & $2 \cdot 0$ & $2 \cdot 3$ & & 0.8 & $1 \cdot 3$ & & 1.9 & $2 \cdot 1$ & & $1 \cdot 1$ & $1 \cdot 3$ & \\
\hline Snack & $0 \cdot 4$ & 0.9 & $<0.001$ & 0.5 & $1 \cdot 4$ & $<0.001$ & 0.6 & $1 \cdot 0$ & $<0.001$ & 0.5 & 0.9 & $<0.001$ \\
\hline Thiamin (mg) & & & & & & & & & & & & \\
\hline Breakfast & 0.9 & 0.6 & & 0.7 & 0.6 & & $1 \cdot 0$ & 0.6 & & 0.7 & 0.6 & \\
\hline Lunch & 0.5 & 0.3 & & 0.5 & 0.4 & & 0.6 & 0.4 & & 0.6 & 0.5 & \\
\hline Dinner & 0.5 & 0.3 & & 0.5 & 0.3 & & 0.5 & 0.4 & & 0.5 & 0.4 & \\
\hline Snack & 0.5 & 0.5 & $<0.001$ & 0.4 & 0.5 & $<0.001$ & 0.5 & 0.4 & $<0.001$ & 0.4 & 0.5 & 0.005 \\
\hline Riboflavin (mg) & & & & & & & & & & & & \\
\hline Breakfast & $2 \cdot 3$ & $2 \cdot 7$ & & $2 \cdot 7$ & $4 \cdot 7$ & & $2 \cdot 0$ & $1 \cdot 2$ & & $2 \cdot 8$ & $4 \cdot 8$ & \\
\hline Lunch & $1 \cdot 6$ & $2 \cdot 8$ & & $2 \cdot 2$ & $4 \cdot 8$ & & $1 \cdot 1$ & $2 \cdot 1$ & & 3.9 & $6 \cdot 5$ & \\
\hline Dinner & $1 \cdot 6$ & 3.5 & & $2 \cdot 4$ & $5 \cdot 6$ & & $1 \cdot 6$ & 3.0 & & 4.5 & $8 \cdot 2$ & \\
\hline Snack & $0 \cdot 6$ & 0.5 & $<0.001$ & 0.6 & 0.6 & 0.002 & 0.6 & 0.5 & $<0.001$ & 0.5 & 0.6 & $<0.001$ \\
\hline Folate (DFE) & & & & & & & & & & & & \\
\hline Breakfast & 240 & 155 & & 184 & 196 & & 235 & 139 & & 117 & 114 & \\
\hline Lunch & 134 & 146 & & 117 & 116 & & 126 & 105 & & 126 & 98 & \\
\hline Dinner & 120 & 96 & & 104 & 109 & & 118 & 95 & & 92 & 87 & \\
\hline Snack & 87 & 96 & $<0.001$ & 95 & 132 & $<0.001$ & 84 & 80 & $<0.001$ & 96 & 141 & 0.073 \\
\hline $\mathrm{Ca}(\mathrm{mg})$ & & & & & & & & & & & & \\
\hline Breakfast & 881 & 475 & & 486 & 350 & & 853 & 479 & & 533 & 428 & \\
\hline Lunch & 245 & 185 & & 297 & 272 & & 239 & 207 & & 351 & 441 & \\
\hline Dinner & 485 & 451 & & 325 & 320 & & 474 & 452 & & 379 & 429 & \\
\hline Snack & 278 & 252 & $<0.001$ & 281 & 303 & $<0.001$ & 301 & 291 & $<0.001$ & 272 & 268 & $<0.001$ \\
\hline $\mathrm{Fe}(\mathrm{mg})$ & & & & & & & & & & & & \\
\hline Breakfast & $15 \cdot 8$ & $11 \cdot 3$ & & $10 \cdot 5$ & 8.9 & & $14 \cdot 5$ & $8 \cdot 8$ & & $9 \cdot 7$ & $7 \cdot 5$ & \\
\hline Lunch & $6 \cdot 3$ & 3.9 & & $4 \cdot 7$ & $2 \cdot 9$ & & $6 \cdot 2$ & $3 \cdot 7$ & & $7 \cdot 8$ & $18 \cdot 1$ & \\
\hline Dinner & $7 \cdot 0$ & $5 \cdot 0$ & & $6 \cdot 5$ & $4 \cdot 0$ & & $6 \cdot 8$ & $4 \cdot 4$ & & $5 \cdot 6$ & 3.6 & \\
\hline Snack & $4 \cdot 6$ & $3 \cdot 1$ & $<0.001$ & $6 \cdot 4$ & $5 \cdot 6$ & $<0.001$ & $5 \cdot 1$ & 3.9 & $<0.001$ & $6 \cdot 4$ & $5 \cdot 3$ & 0.012 \\
\hline $\mathrm{Zn}(\mathrm{mg})$ & & & & & & & & & & & & \\
\hline Breakfast & $5 \cdot 1$ & $4 \cdot 1$ & & $4 \cdot 7$ & $2 \cdot 7$ & & $6 \cdot 6$ & $5 \cdot 6$ & & $5 \cdot 1$ & $5 \cdot 3$ & \\
\hline Lunch & $6 \cdot 1$ & $5 \cdot 0$ & & $5 \cdot 0$ & 3.0 & & $5 \cdot 7$ & $4 \cdot 3$ & & $5 \cdot 3$ & $4 \cdot 1$ & \\
\hline Dinner & $4 \cdot 3$ & $3 \cdot 1$ & & $4 \cdot 4$ & $3 \cdot 8$ & & $4 \cdot 7$ & $4 \cdot 0$ & & $4 \cdot 7$ & $4 \cdot 4$ & \\
\hline Snack & $2 \cdot 3$ & 1.9 & $<0.001$ & $3 \cdot 2$ & $4 \cdot 0$ & 0.001 & $2 \cdot 3$ & $2 \cdot 0$ & $<0.001$ & 3.7 & $4 \cdot 7$ & 0.050 \\
\hline
\end{tabular}

HSES, higher socio-economic status; LSES, lower socio-economic status; RAE, retinol activity equivalents; DFE, dietary folate equivalents.

${ }^{\star} P$ value from repeated-measures ANOVA. 
snacks) within subjects. Without class distinction, lunch had higher density of protein $(P<0 \cdot 001)$ and snacks had higher density of carbohydrates $(P<0 \cdot 001$ in HSES boys and girls, $P=0.034$ in LSES boys, $P=0.003$ in LSES girls). Mean density of fat was not significantly different between the mealtimes $(P=0 \cdot 198$ in HSES boys, $P=0.206$ in LSES boys, $P=0 \cdot 275$ LSES girls), except in HSES girls for which dinner had higher density of fat $(P<0 \cdot 001)$. Significant differences were observed for all micronutrients examined, except folate in LSES girls $(P=0 \cdot 073)$. Most micronutrients had higher density at breakfast for most gender and SES subgroups. The exceptions were vitamin $\mathrm{C}(P<0 \cdot 001)$ for which snacks were a major source, riboflavin in LSES girls $(P<0 \cdot 001)$ for which dinner was a major source, folate in LSES girls $(P=0 \cdot 073)$ for which no differences were observed between meals and $\mathrm{Zn}(P<0 \cdot 001)$ for which lunch was a major source in boys and LSES girls. Breakfast was a remarkably superior source for vitamin D, Ca and Fe $(P<0 \cdot 001)$.

\section{Critical nutrient density by mealtime}

Meals with a nutrient density below the critical density computed according to RNI values and energy requirements are presented in Table 4 . Snacks had a nutrient density below the critical density for most micronutrients examined, with some differences between genders and social class. Breakfast had a nutrient density below the critical density for vitamin D in all gender and SES subgroups. In LSES girls only, the critical density for breakfast was also below the standard for vitamin $\mathrm{C}$ and folate. Snacks had critical densities for nearly all micronutrients examined with the sole exception of vitamin C.

\section{Discussion}

Guatemala has traditionally been renowned in the nutritional literature for the description and exploration of nutrient deficiencies ${ }^{(18-21)}$. At the same time, certain aspects of its traditional Guatemalan cuisine have been associated with good health related to blood pressure ${ }^{(22)}$, intestinal function ${ }^{(23)}$ and cardiovascular health ${ }^{(24)}$. Increasingly in Latin America, a pattern described as 'nutrition transition' has been documented ${ }^{(25-28)}$. The nutrition transition experience is related to demographic and socio-economic changes, dietary changes, increased obesity rates and sedentary lifestyles. It is characterized by dietary changes such as an increase in dietary fat (mostly saturated fat) and the increased availability and preference for high-fat/high-carbohydrate energy-dense foods. In Latin America, these changes have been occurring quickly and unevenly across socio-economic groups. As a consequence a shift from infectious diseases to chronic diseases has been observed. Companion studies in our population have confirmed the emergence of overweight and obesity in the middle-class of Quetzaltenango ${ }^{(29,30)}$ and a lower than recommended consumption of fruits and vegetables ( $G$ Montenegro-Bethancourt, unpublished results). The opportunity to look more deeply into the dietary pattern, specifically of how nutrients selectively associate with different meals across the day, has been examined here among 449 schoolchildren of both sexes, attending either public or private schools in the most important metropolitan area of the western highlands of Guatemala.

Certain limitations in the design and methodology are recognized. They derive in part from resource limitations and from limited time of access to each school site and to the subjects within each setting. First, the non-response rate was high which might have resulted in selection bias. The low participation rate is largely caused by the limitations of the data collection time frame combined with the necessary informed consent procedures. There were multiple opportunities for a child to be missed during the five consecutive days of recruitment and data collection. 'Forgetting' informed consent forms and leaving data collection booklets at home were common occurrences. While efforts were made to include children with missing data, the time restraints of the data collection period did not permit researchers to return to the same schools. Non-response rate was higher in children of LSES (46\%) compared with children of HSES (35\%). It is, for example, possible that those children with a poor diet may have opted not to participate, or simply that children were disinterested in the extra-curricular activities.

Second, the present study is based on a single day's register of foods and beverages with the disadvantage of not being representative of the habitual nutrient intake of any individual within the group. As a consequence of this limitation, analysis in the study was conducted at the group rather than individual level, as a single $24 \mathrm{~h}$ recall better represents the distribution of the group (and subgroups) intake within the season of the year. With only one day, however, we could not adjust the group averages for variance ${ }^{(31)}$ and thus the reported distributions are wider than would be conventionally reported with the opportunity for variance adjustments. However, requesting a second day's registry, even in a sub-sample of our survey population, represents an inconvenience that might have interfered with institutional collaboration or lowered the response rate.

Third, our data rely on self-reporting by children. Paediatric diet researchers have been generally optimistic about the validity of $24 \mathrm{~h}$ reporting by children ${ }^{(32-34)}$. Lytle et $a l^{(34)}$ validated $24 \mathrm{~h}$ recalls assisted by food records in third-grade children; they judged prospective pictorial representation as facilitating and this method valid for assessing the dietary intake of children as young as 8 years old for the purpose of group comparison.

Furthermore, the nutritional content of the recipes was determined on the basis of raw ingredients, without considering the losses due to heating treatment during 
Table 4 Gender-specific critical densities for micronutrients and meals with average content below critical densities: third- and fourth-grade schoolchildren from Quetzaltenango, Guatemala, 2005

\begin{tabular}{|c|c|c|c|}
\hline & $\begin{array}{c}\text { Critical density } \\
\text { (per } 4187 \mathrm{~kJ} / 1000 \mathrm{kcal})^{\star}\end{array}$ & HSES & LSES \\
\hline \multicolumn{4}{|l|}{ Boys ( $n 217)$} \\
\hline Vitamin A (RAE) & $266 \cdot 7$ & snacks & \\
\hline Vitamin C (mg) & $18 \cdot 7$ & & \\
\hline Vitamin D $(\mu \mathrm{g})$ & $2 \cdot 7$ & breakfast, lunch, dinner, snacks & breakfast, lunch, dinner, snacks \\
\hline Thiamin (mg) & 0.5 & & snacks \\
\hline Riboflavin (mg) & 0.5 & & \\
\hline Folate (DFE) & $160 \cdot 0$ & lunch, dinner, snacks & lunch, dinner, snacks \\
\hline $\mathrm{Ca}(\mathrm{mg})$ & $373 \cdot 3$ & lunch, snacks & lunch, dinner, snacks \\
\hline $\mathrm{Fe}(\mathrm{mg})$ & $4 \cdot 8$ & snacks & lunch \\
\hline $\mathrm{Zn}(\mathrm{mg})$ & $3 \cdot 0$ & snacks & \\
\hline \multicolumn{4}{|l|}{ Girls (n 232) } \\
\hline Vitamin A (RAE) & $303 \cdot 0$ & snacks & \\
\hline Vitamin C (mg) & $21 \cdot 2$ & & breakfast \\
\hline Vitamin D $(\mu \mathrm{g})$ & $3 \cdot 0$ & breakfast, lunch, dinner, snacks & breakfast, lunch, dinner, snacks \\
\hline Thiamin $(\mathrm{mg})$ & 0.5 & dinner, snacks & dinner, snacks \\
\hline Riboflavin (mg) & 0.5 & & snacks \\
\hline Folate (DFE) & $181 \cdot 8$ & lunch, dinner, snacks & breakfast, lunch, dinner, snacks \\
\hline $\mathrm{Ca}(\mathrm{mg})$ & $424 \cdot 2$ & lunch, snacks & lunch, dinner, snacks \\
\hline $\mathrm{Fe}(\mathrm{mg})$ & $5 \cdot 5$ & snacks & \\
\hline $\mathrm{Zn}(\mathrm{mg})$ & $3 \cdot 4$ & snacks & \\
\hline
\end{tabular}

HSES, higher socio-economic status; LSES, lower socio-economic status; RAE, retinol activity equivalents; DFE, dietary folate equivalents. ${ }^{*}$ Critical density was based on the WHO/FAO vitamin and mineral requirements (Recommended Nutrient Intakes) ${ }^{(16)}$ and a recommended daily energy intake of $7850 \mathrm{~kJ}(1875 \mathrm{kcal})$ for boys and $6908 \mathrm{~kJ}(1650 \mathrm{kcal})$ for girls ${ }^{(17)}$.

cooking or frying. Thus we could be overestimating the nutritional contribution for the labile vitamins. In addition, there are limitations to the nutrient data obtained from the FCT. Finally, we generally selected our analyses to focus within the daily consumption of nutrients by meals within the various sub-samples of the study, rather than making any systematic effort to identify differences in total consumption or intake adequacy across subgroups.

What was noteworthy in our study was the relative parity for the energy contribution from the various mealtimes across the day of registry. When pooled across social groups (data not shown), the energy contributions from breakfast, dinner and snacks were within a few percentage points of one another $(\sim 23 \%)$, whereas lunch was marginally greater, providing 30 (SD 10) \% of daily energy. A parallel lunchtime bulge in relative consumption was seen for protein and carbohydrate, with fat contribution remaining more evenly distributed among the four meals. In contrast, Matthys et al. ${ }^{(5)}$ found a lower contribution of snacks to energy distribution among meals in Flemish adolescents. In their sample, breakfast and lunch accounted for $32 \%$ and $31 \%$, respectively, of the day's energy, whereas snacks contributed only $16 \%$, with the remaining $21 \%$ coming from the evening meal ${ }^{(5)}$. Another study in Belgian adolescents found a lower contribution of breakfast to energy distribution (15.7\% for boys and $14.9 \%$ for girls) among meals ${ }^{(35)}$. Inequality of energy contribution among meals was also the rule in a sample of Swedish adolescents, aged 15 to 16 years, in which the percentage of energy from meals was $20 \%$ and $21 \%$ from breakfast, $16 \%$ and $17 \%$ from lunch, $26 \%$ and $28 \%$ from dinner and $37 \%$ and $35 \%$ from in-between meals in boys and girls, respectively ${ }^{(7)}$. These are European studies in slightly older children, but in the absence of analogous approaches applied to Central American or Latin American children, they represent the only basis for meal-pattern comparison for the juvenile situation.

Several studies have focused on breakfast skipping and breakfast quality. Good breakfast quality has been shown to relate to a better overall dietary pattern ${ }^{(3,35)}$. Irregular breakfast eating is related to negative lifestyle factors such as smoking, a higher percentage of energy from snack foods and lower intake of micronutrients ${ }^{(7)}$, and also mental distress and lower academic performance ${ }^{(36-38)}$. In our study, children rarely skipped breakfast $(<1 \%)$ and breakfast was the largest source of essential micronutrients.

With respect to micronutrient contributions in relation to the meal pattern, an additional contrast is seen between our findings and those of the Flemish series ${ }^{(5)}$. In these Guatemalan third- and fourth-grade schoolchildren, snacks contribute less to the day's intake of vitamin $\mathrm{A}$, vitamin $\mathrm{D}$, riboflavin, $\mathrm{Ca}, \mathrm{Fe}$ and $\mathrm{Zn}$ than to daily energy. This is similar to the role of snacks' micronutrient contribution in Finnish adults as reported by Ovaskainen et al. ${ }^{(8)}$. By contrast, in the Belgian adolescents, micronutrient intake generally bore a constant relationship to energy intake; there, micronutrient densities were apparently uniform across meals ${ }^{(5)}$.

It is not sufficient, however, simply to know whether there is insufficiency, adequacy or excess of macro- or micronutrients intake from a diet. The meal-based context of nutrients can only be appreciated when dietary intake focuses on a meal-by-meal assessment of macro- and micronutrients as done here and in companion studies. On the practical side, moreover, knowledge of the nutrient distribution can be used by nutritional professionals as a 
fulcrum to plan interventions to redress either an excess or a deficiency of a nutrient, using a meal-based perspective in addressing any unhealthful aspect of dietary consumption. In this way, the pattern described would guide the strategy of public health interventions to redress any problems of insufficient or excessive intake of nutrients or dietary constituents. For reducing intake of food components that are associated with poor health, one must know when they are most likely to be eaten. Similarly, to redress deficiencies, one must know which meals are generally rich, or poor, in these nutrients.

The nutrients are consumed in the context of foods and beverages. The selection of foods in Table 1 reflects the preferences of children as well as the cultural norms of the caregivers and the availability, affordability and accessibility of the items in the marketplace. The ten leading items constitute between $68.0 \%$ and $69.5 \%$ of breakfast's energy, between $48 \cdot 7 \%$ and $59 \cdot 3 \%$ for lunch, between $47 \cdot 3 \%$ and $59 \cdot 8 \%$ for dinner and between $36.3 \%$ and $52.9 \%$ for combined snacking. In general, the ten main sources accounted for slightly more meal energy for the LSES children, reflecting a lesser variety. Notable across genders and social class is the consumption of corn tortilla. It ranks high in energy contribution to both the midday and the evening meals. The Mayan cuisine, of course, is based on maize, as exemplified in the novel Hombres de Maiz (Men of Corn) by the Guatemalan Nobel Laureate, Miguel Angel Asturias ${ }^{(39)}$. The Mayan creation myth proclaims that the gods created Man from corn dough. This finding of a corn-rich diet in lower social classes has also been documented in Mexican adolescent girls ${ }^{(40)}$. Ready-to-eat breakfast cereals were predominant as a breakfast item, ranking consistently higher in the HSES sample than in its less affluent counterpart; this also confirms the finding for Mexican adolescents $^{(40)}$. Several studies have mentioned the importance of ready-to-eat breakfast cereals in terms of nutritional benefits ${ }^{(3,41,42)}$.

The unbalanced distribution of nutrient intake across mealtimes is subject to rapid change. For instance, the Central American and Dominican Republic Free Trade Agreement came into affect between Guatemala and the USA on 1 June 2006. If schoolchildren's dietary habits evolve under the influence of a broader selection of foods in the marketplace, it could produce major changes from what is currently being eaten at the various meals. To the extent that the nutrient compositions of the new foods are likely to be different, wholesale redistribution of nutrient intake patterns could result. Micronutrients that are currently abundant in the breakfast fare, for instance, may become scarcer.

Latin American public policy has been informed in the past by the concept of critical nutrient density. In a region-wide consensus meeting held by the Cavendas Foundation in Caracas, Venezuela in 1986, an alternative approach to nutrient recommendations, based on nutrient density, was advanced ${ }^{(15)}$. It proposed that a Latin American family eats as a unit; if all nutrients were adequate for every meal, then all members would simultaneously achieve their specific needs. The nutrient density focus for dietary analysis has grown in interest in recent years $^{(43-45)}$. The present study informs us is that micronutrient density varies by meal, such that changing the selection patterns for one meal, as with a school meal intervention, could differentially influence the whole day's supply.

\section{Conclusions}

The children of both low and high social class of this urban centre in the Guatemalan highlands had remarkably equivalent and balanced distributions of energy across the four daily meal settings. Protein, carbohydrate and the various vitamins and minerals were generally concentrated into one or two of the meals. This produced unique nutrient densities among the meals. To the degree that certain problems of deficient intake, e.g. vitamin D, remain to be redressed, an understanding of how foods and food groups are combined - within meals and across the day - could be useful in designing the appropriate education and inducement for remedy. The present findings, therefore, place a mathematical face on the complexities of juggling a confluent series of public health aims. We agree with the comments of Perez et $a l .{ }^{(46)}$ that evaluating 'differences in dietary intake and meal patterns by grade can provide readily accessible information to develop a needs assessment or intervention materials for children'. The meal-based approach may provide guidance to strategies to improve dietary balance in an era of coexisting energy overnutrition and micronutrient inadequacy.

\section{Acknowledgements}

The study was funded by grants from the American Institute of Cancer Research (AICR), the Sight and Life Organization, and the Department of Health Sciences, Vrije Universiteit, The Netherlands. We are most grateful to the Quetzaltenango Health and Education Authorities and to the students of the Universidad Rafael Landivar, Quetzaltenango for their help with data collection. Above all we are grateful to the staff of the twelve schools, and to the children and their parents or guardians, who participated so cheerfully. We are also grateful to Professor Jaap Seidell from the Vrije Universiteit of Amsterdam, for his collaborative partnership with CeSSIAM. The authors' responsibilities were as follows: M.V. participated in data analysis, interpretation of results, writing and editing of the manuscript. G.M.-B. conducted the research as part of the Master programme for International Public Health and wrote the protocol, collected the data and participated in 
data analysis. L.D.J.K. provided statistical advice. C.M.D. and N.W.S. contributed in the design of the study, supervision, interpretation of results and writing of the manuscript. There were no conflicts of interest.

\section{References}

1. Uauy R \& Solomons N (2005) Diet, nutrition, and the lifecourse approach to cancer prevention. J Nutr 135, 2934S-2945S.

2. Azadbakht L, Mirmiran P \& Azizi F (2005) Variety scores of food groups contribute to the specific nutrient adequacy in Tehranian men. Eur J Clin Nutr 59, 1233-1240.

3. Chitra U \& Reddy CR (2007) The role of breakfast in nutrient intake of urban schoolchildren. Public Health Nutr 10, 55-58.

4. van den Boom A, Serra-Majem L, Ribas L, Ngo J, PerezRodrigo C, Aranceta J \& Fletcher R (2006) The contribution of ready-to-eat cereals to daily nutrient intake and breakfast quality in a Mediterranean setting. J Am Coll Nutr 25, $135-143$.

5. Matthys C, De Henauw S, Devos C \& De Backer G (2003) Estimated energy intake, macronutrient intake and meal pattern of Flemish adolescents. Eur J Clin Nutr 57, 366-375.

6. De Henauw S, Wilms L, Mertens J, Standaert B \& De Backer G (1997) Overall and meal-specific macronutrient intake in Belgian primary school children. Ann Nutr Metab 41, 89-97.

7. Sjoberg A, Hallberg L, Hoglund D \& Hulthen L (2003) Meal pattern, food choice, nutrient intake and lifestyle factors in The Goteborg Adolescence Study. Eur J Clin Nutr 57, 1569-1578.

8. Ovaskainen ML, Reinivuo H, Tapanainen H, Hannila ML, Korhonen T \& Pakkala H (2006) Snacks as an element of energy intake and food consumption. Eur J Clin Nutr 60, 494-501.

9. Torún B (2005) Energy requirements of children and adolescents. Public Health Nutr 8, 968-993.

10. Institute of Medicine (2002) Dietary Reference Intakes for Energy, Carbohydrate, Fiber, Fat, Fatty Acids, Cholesterol, Protein, and Amino Acids. Washington, DC: National Academies Press.

11. Instituto de Nutrición de Centro América y Panamá \& Oficina Panamericana de la Salud (2000) Valor nutritivo de los alimentos de centroamerica (Nutritional Value of Foods from Central America). Guatemala: INCAP \& OPS.

12. De Bethancourt I (editor) (1998) Lo mejor de mi cocina (The Best of My Kitchen). Guatemala City: Impresora Profesional.

13. Portillo-Lemus Margoth G (1982) Platos tipicos y regionales (Typical and Regional Dishes). Guatemala City: Editora Comunicación.

14. Sierra Franco DA (2002) Cocina regional Guatemalteca (Regional Guatemalan Cuisine). Guatemala City: Editorial Piedrasanta.

15. Bengoa J, Torun B, Behar M \& Scrimshaw N (1987) Metas nutricionales y guías de alimentación para América Latina. Bases para su desarrollo (Nutritional goals and dietary guidelines for Latin America. Bases for their development). Arch Latinoam Nutr 37, 373-426.

16. World Health Organization \& Food and Agriculture Organization of the United Nations (2004) Vitamin and Mineral Requirements in Human Nutrition. Joint FAO/ WHO Consultation on Human Vitamin and Mineral Requirements. Geneva: FAO/WHO.

17. Torún B, Menchú MT \& Elías LG (editors) (1994) Recomendaciones Dietéticas Diarias del INCAP (Daily
Dietary Recommendations from INCAP). Guatemala City: Institute of Nutrition of Central America and Panama.

18. Boisvert WA, Castaneda C, Mendoza I, Langeloh G, Solomons NW, Gershoff SN \& Russell RM (1993) Prevalence of riboflavin deficiency among Guatemalan elderly people and its relationship to milk intake. Am J Clin Nutr $\mathbf{5 8}, 85-90$.

19. Franzetti S, Mejia LA, Viteri FE \& Alvarez E (1984) Body iron reserves of rural and urban Guatemalan women of reproductive age. Arch Latinoam Nutr 34, 69-82.

20. Lutter CK \& Rivera JA (2003) Nutritional status of infants and young children and characteristics of their diets. J Nutr 133, 2941S-2949S.

21. Majia LA, Hodges RE, Arroyave G, Viteri F \& Torun B (1977) Vitamin A deficiency and anemia in Central American children. Am J Clin Nutr 30, 1175-1184.

22. Belizan JM \& Villar J (1980) The relationship between calcium intake and edema-, proteinuria-, and hypertension-getosis: an hypothesis. Am J Clin Nutr 33, 2202-2210.

23. Kretsch MJ, Crawford L \& Calloway DH (1979) Some aspects of bile acid and urobilinogen excretion and fecal elimination in men given a rural Guatemalan diet and egg formulas with and without added oat bran. Am J Clin Nutr 32, 1492-1496.

24. McGill HC, Stella-Arias J, Carbonell LM et al. (1968) General findings of the International Atherosclerosis Project. Lab Invest 18, 498-502.

25. Albala C, Vio F, Kain J \& Uauy R (2002) Nutrition transition in Chile: determinants and consequences. Public Health Nutr 5, 123-128.

26. Rivera JA, Barquera S, Campirano F, Campos I, Safdie M \& Tovar V (2002) Epidemiological and nutritional transition in Mexico: rapid increase of non-communicable chronic diseases and obesity. Public Health Nutr 5, 113-122.

27. Rodriguez-Ojea A, Jimenez S, Berdasco A \& Esquivel M (2002) The nutrition transition in Cuba in the nineties: an overview. Public Health Nutr 5, 129-133.

28. Barria RM \& Amigo H (2006) Nutrition transition: a review of Latin American profile. Arch Latinoam Nutr 56, 3-11.

29. Groeneveld IF, Solomons N \& Doak CM (2007) Nutritional status of urban schoolchildren of high and low socioeconomic status in Quetzaltenango, Guatemala. Rev Panam Salud Publica 22, 169-177.

30. Groeneveld IF, Solomons NW \& Doak CM (2007) Determination of central body fat by measuring natural waist and umbilical abdominal circumference in Guatemalan schoolchildren. Int J Pediatr Obes 2, 114-121.

31. Murphy SP (2003) Collection and analysis of intake data from the integrated survey. J Nutr 133, 585S-589S.

32. Baxter SD, Smith AF, Litaker MS, Guinn CH, Shaffer NM, Baglio ML \& Frye FH (2004) Recency affects reporting accuracy of children's dietary recalls. Ann Epidemiol 14, 385-390.

33. Livingstone MB \& Robson PJ (2000) Measurement of dietary intake in children. Proc Nutr Soc 59, 279-293.

34. Lytle LA, Nichaman MZ, Obarzanek E, Glovsky E, Montgomery D, Nicklas T, Zive M \& Feldman H (1993) Validation of 24-hour recalls assisted by food records in third-grade children. The CATCH Collaborative Group. J Am Diet Assoc 93, 1431-1436.

35. Matthys C, De Henauw S, Bellemans M, De Maeyer M \& De Backer G (2007) Breakfast habits affect overall nutrient profiles in adolescents. Public Health Nutr 10, 413-421.

36. Herrero Lozano R \& Fillat Ballesteros JC (2006) A study on breakfast and school performance in a group of adolescents. Nutr Hosp 21, 346-352.

37. Lien L (2007) Is breakfast consumption related to mental distress and academic performance in adolescents? Public Health Nutr 10, 422-428. 
38. Torres MD, Carmona I, Campillo C, Perez G \& Campillo JE (2007) Breakfast, plasma glucose and $\beta$-hydroxybutyrate, body mass index and academic performance in children from Extremadura, Spain. Nutr Hosp 22, 487-490.

39. Asturias M (1972)Hombres de Maiz (Men of Corn). Madrid: Alianza Editorial.

40. Lozada AL, Flores M, Rodriguez S \& Barquera S (2007) Dietary patterns in Mexican adolescent girls. A comparison of two methods. National Nutrition Survey, 1999. Salud Publica Mex 49, 263-273.

41. Galvin MA, Kiely M \& Flynn A (2003) Impact of ready-toeat breakfast cereal (RTEBC) consumption on adequacy of micronutrient intakes and compliance with dietary recommendations in Irish adults. Public Health Nutr 6, 351-363.

42. Gibson S (2003) Micronutrient intakes, micronutrient status and lipid profiles among young people consuming different amounts of breakfast cereals: further analysis of data from the National Diet and Nutrition Survey of Young People aged 4 to 18 years. Public Health Nutr 6, 815-820.

43. Darmon N, Darmon M, Maillot M \& Drewnowski A (2005) A nutrient density standard for vegetables and fruits: nutrients per calorie and nutrients per unit cost. J Am Diet Assoc 105, 1881-1887.

44. Drewnowski A (2005) Concept of a nutritious food: toward a nutrient density score. Am J Clin Nutr 82, 721-732.

45. Backstrand JR (2003) Quantitative approaches to nutrient density for public health nutrition. Public Health Nutr 6 , 829-837.

46. Perez A, Hoelscher DM, Brown HS 3rd \& Kelder SH (2007) Differences in food consumption and meal patterns in Texas school children by grade. Prev Chronic Dis $\mathbf{4}$, A23.

\section{Appendix}

Estimated 1 d intakes of energy, macronutrients and selected micronutrients by mealtime, gender and socio-economic status: third-and fourth-grade schoolchildren from Quetzaltenango, Guatemala, 2005

\begin{tabular}{|c|c|c|c|c|c|c|c|c|}
\hline \multirow{3}{*}{$\begin{array}{l}\text { Absolute daily estimated } \\
\text { intake per meal }\end{array}$} & \multicolumn{4}{|c|}{ Boys (n 217) } & \multicolumn{4}{|c|}{ Girls (n 232) } \\
\hline & \multicolumn{2}{|c|}{ HSES $(n 111)$} & \multicolumn{2}{|c|}{ LSES $(n 106)$} & \multicolumn{2}{|c|}{ HSES $(n 111)$} & \multicolumn{2}{|c|}{ LSES $(n 106)$} \\
\hline & Mean & SD & Mean & SD & Mean & SD & Mean & $\mathrm{SD}$ \\
\hline \multicolumn{9}{|l|}{ Energy (kJ) } \\
\hline Breakfast & 1771 & 821 & 2236 & 1223 & 1687 & 892 & 1905 & 871 \\
\hline Lunch & 2700 & 1340 & 2445 & 1122 & 2332 & 963 & 2319 & 1093 \\
\hline Dinner & 2022 & 1239 & 1922 & 1122 & 1892 & 1202 & 1997 & 1126 \\
\hline Snack & 1897 & 1097 & 1562 & 1001 & 2244 & 1382 & 1721 & 1193 \\
\hline \multicolumn{9}{|l|}{ Energy (kcal) } \\
\hline Breakfast & 423 & 196 & 534 & 292 & 403 & 213 & 455 & 208 \\
\hline Lunch & 645 & 320 & 584 & 268 & 557 & 230 & 554 & 261 \\
\hline Dinner & 483 & 296 & 459 & 268 & 452 & 287 & 477 & 269 \\
\hline Snack & 453 & 262 & 373 & 239 & 536 & 330 & 411 & 285 \\
\hline \multicolumn{9}{|l|}{ Protein (g) } \\
\hline Breakfast & 14 & 8 & 18 & 11 & 13 & 8 & 15 & 10 \\
\hline Lunch & 27 & 15 & 22 & 14 & 24 & 14 & 20 & 11 \\
\hline Dinner & 18 & 12 & 17 & 13 & 16 & 11 & 16 & 12 \\
\hline Snack & 12 & 12 & 8 & 9 & 13 & 10 & 8 & 7 \\
\hline \multicolumn{9}{|l|}{ Fat $(\mathrm{g})$} \\
\hline Breakfast & 13 & 7 & 15 & 10 & 11 & 7 & 13 & 8 \\
\hline Lunch & 20 & 15 & 16 & 15 & 15 & 9 & 17 & 15 \\
\hline Dinner & 17 & 12 & 14 & 11 & 18 & 17 & 16 & 13 \\
\hline Snack & 15 & 11 & 11 & 10 & 16 & 13 & 13 & 13 \\
\hline \multicolumn{9}{|l|}{ Carbohydrate (g) } \\
\hline Breakfast & 65 & 38 & 83 & 56 & 63 & 38 & 72 & 39 \\
\hline Lunch & 93 & 54 & 92 & 44 & 85 & 47 & 85 & 47 \\
\hline Dinner & 67 & 51 & 70 & 45 & 59 & 39 & 70 & 45 \\
\hline Snack & 70 & 39 & 62 & 38 & 87 & 54 & 68 & 46 \\
\hline \multicolumn{9}{|l|}{ Vitamin A (RAE) } \\
\hline Breakfast & 311 & 164 & 301 & 175 & 308 & 181 & 294 & 177 \\
\hline Lunch & 322 & 526 & 303 & 717 & 320 & 305 & 269 & 264 \\
\hline Dinner & 231 & 229 & 177 & 148 & 217 & 226 & 194 & 114 \\
\hline Snack & 93 & 155 & 108 & 112 & 133 & 146 & 133 & 122 \\
\hline \multicolumn{9}{|l|}{ Vitamin C (mg) } \\
\hline Breakfast & 31 & 50 & 17 & 34 & 27 & 50 & 8 & 11 \\
\hline Lunch & 36 & 39 & 21 & 27 & 34 & 43 & 33 & 43 \\
\hline Dinner & 11 & 20 & 10 & 19 & 16 & 36 & 13 & 28 \\
\hline Snack & 33 & 52 & 11 & 28 & 41 & 54 & 27 & 43 \\
\hline \multicolumn{9}{|l|}{ Vitamin D $(\mu \mathrm{g})$} \\
\hline Breakfast & 1.9 & $1 \cdot 0$ & $1 \cdot 2$ & $1 \cdot 1$ & $1 \cdot 6$ & $1 \cdot 2$ & 0.9 & $1 \cdot 0$ \\
\hline Lunch & 0.3 & 0.4 & 0.3 & 0.5 & 0.3 & 0.4 & 0.2 & 0.4 \\
\hline Dinner & 0.8 & $1 \cdot 0$ & 0.4 & 0.6 & $0 \cdot 7$ & 0.8 & $0 . \overline{5}$ & 0.6 \\
\hline Snack & 0.2 & 0.5 & 0.2 & 0.4 & 0.3 & 0.6 & 0.2 & 0.4 \\
\hline
\end{tabular}


Continued

\begin{tabular}{|c|c|c|c|c|c|c|c|c|}
\hline \multirow{3}{*}{$\begin{array}{l}\text { Absolute daily estimated } \\
\text { intake per meal }\end{array}$} & \multicolumn{4}{|c|}{ Boys ( $n$ 217) } & \multicolumn{4}{|c|}{ Girls (n 232) } \\
\hline & \multicolumn{2}{|c|}{ HSES $(n 111)$} & \multicolumn{2}{|c|}{ LSES $(n$ 106) } & \multicolumn{2}{|c|}{ HSES $(n 111)$} & \multicolumn{2}{|c|}{ LSES $(n$ 106) } \\
\hline & Mean & SD & Mean & SD & Mean & SD & Mean & SD \\
\hline \multicolumn{9}{|l|}{ Thiamin (mg) } \\
\hline Breakfast & 0.4 & 0.3 & 0.3 & 0.2 & 0.4 & $0 \cdot 3$ & 0.3 & 0.4 \\
\hline Lunch & 0.3 & 0.2 & $0 \cdot 3$ & 0.2 & $0 \cdot 3$ & $0 \cdot 2$ & $0 \cdot 3$ & 0.2 \\
\hline Dinner & 0.2 & 0.2 & 0.3 & $0 . \overline{3}$ & $0 \cdot 3$ & $0 . \overline{3}$ & 0.3 & $0 \cdot 3$ \\
\hline Snack & 0.2 & 0.2 & $0 \cdot 1$ & 0.2 & $0 \cdot 3$ & $0 \cdot 3$ & 0.2 & $0 \cdot 1$ \\
\hline \multicolumn{9}{|l|}{ Riboflavin (mg) } \\
\hline Breakfast & 0.9 & 0.7 & $1 \cdot 2$ & $2 \cdot 0$ & 0.8 & 0.6 & $1 \cdot 2$ & 1.9 \\
\hline Lunch & $1 \cdot 0$ & $1 \cdot 6$ & $1 \cdot 2$ & $2 \cdot 5$ & 0.6 & $1 \cdot 4$ & 1.9 & $3 \cdot 2$ \\
\hline Dinner & 0.7 & $1 \cdot 3$ & $1 \cdot \overline{1}$ & $2 \cdot 5$ & 0.6 & $1 \cdot 1$ & $1 \cdot 7$ & $2 \cdot \overline{9}$ \\
\hline Snack & 0.3 & 0.3 & 0.2 & 0.2 & 0.3 & 0.3 & 0.2 & $0 \cdot 2$ \\
\hline \multicolumn{9}{|l|}{ Folate (DFE) } \\
\hline Breakfast & 97 & 65 & 82 & 68 & 94 & 65 & 51 & 50 \\
\hline Lunch & 79 & 78 & 67 & 60 & 73 & 72 & 68 & 61 \\
\hline Dinner & 55 & 47 & 45 & 49 & 53 & 52 & 49 & 59 \\
\hline Snack & 38 & 37 & 30 & 36 & 46 & 51 & 31 & 32 \\
\hline \multicolumn{9}{|l|}{$\mathrm{Ca}(\mathrm{mg})$} \\
\hline Breakfast & 356 & 202 & 247 & 206 & 347 & 209 & 253 & 245 \\
\hline Lunch & 159 & 168 & 182 & 189 & 140 & 147 & 180 & 205 \\
\hline Dinner & 244 & 260 & 179 & 258 & 224 & 230 & 176 & 224 \\
\hline Snack & 136 & 162 & 102 & 115 & 177 & 185 & 108 & 122 \\
\hline \multicolumn{9}{|l|}{$\mathrm{Fe}(\mathrm{mg})$} \\
\hline Breakfast & $6 \cdot 4$ & $4 \cdot 8$ & $5 \cdot 0$ & $4 \cdot 0$ & $6 \cdot 1$ & $4 \cdot 8$ & $4 \cdot 6$ & $4 \cdot 2$ \\
\hline Lunch & 3.7 & $2 \cdot 6$ & $2 \cdot 7$ & $2 \cdot 0$ & $3 \cdot 2$ & $2 \cdot 0$ & $3 \cdot 1$ & $3 \cdot 7$ \\
\hline Dinner & $3 \cdot 3$ & $2 \cdot 9$ & $3 \cdot 1$ & $2 \cdot 6$ & $3 \cdot 1$ & $2 \cdot 5$ & $2 \cdot 7$ & $2 \cdot 2$ \\
\hline Snack & $2 \cdot 0$ & $1 \cdot 4$ & $2 \cdot 3$ & $1 \cdot 8$ & $2 \cdot 6$ & $2 \cdot 3$ & $2 \cdot 2$ & $1 \cdot 5$ \\
\hline \multicolumn{9}{|l|}{$\mathrm{Zn}(\mathrm{mg})$} \\
\hline Breakfast & $2 \cdot 3$ & $2 \cdot 6$ & $2 \cdot 4$ & 1.9 & $2 \cdot 7$ & $2 \cdot 8$ & $2 \cdot 7$ & $4 \cdot 1$ \\
\hline Lunch & 3.5 & $2 \cdot 4$ & 3.0 & $2 \cdot 2$ & $3 \cdot 1$ & $2 \cdot 4$ & $2 \cdot 7$ & $2 \cdot 0$ \\
\hline Dinner & $2 \cdot 0$ & $1 \cdot 7$ & $2 \cdot 2$ & $3 \cdot 3$ & $2 \cdot 1$ & $2 \cdot 4$ & $2 \cdot 2$ & $2 \cdot 3$ \\
\hline Snack & $1 \cdot 2$ & $1 \cdot 1$ & $1 \cdot 1$ & $1 \cdot 2$ & $1 \cdot 4$ & $1 \cdot 3$ & $1 \cdot 3$ & $1 \cdot 3$ \\
\hline
\end{tabular}

HSES, higher socio-economic status; LSES, lower socio-economic status; RAE, retinol activity equivalents; DFE, dietary folate equivalents. 